\title{
PH-2
}

\section{Dosimetric Verification of Dose Distribution as Three Dimensional Intensity Modulated Radiation Therapy based MRI Using Polymer Gel}

\author{
M.SH.El. Sayed*, F.I.SAID*, A. Z. Dakrory**, T. M. Hegazy** and H. A. Abdelghany** \\ Radiation Protection Dosimetery, National Center for Radiation Research and Technology, \\ Atomic Energy Authority * Physics Dept., Faculty of Girls, Ain Shams University** \\ medhatshaban@yahoo.com
}

\begin{abstract}
Polymer gel dosimeter have been developed as means of detecting and verifying an absorbed doses given to cancer patients for radiotherapy in the range (0-10Gy) as measured and verification dose distributions of three-dimensional (3D) treatments. This article reports on the dosimeter of a new N-isopropanol acrylamide NIPAM, high weight percent T\%, \%C the mass percent of all comonomer polymer gel formulation $(6 \mathrm{~T} \%, 20 \mathrm{C} \%)$, optimized for magnetic resonance imaging (MRI). The aim to investigated MR-based polymer gel dosimeter as a three-dimensional 3D dosimeter in IMRT. Magnetic resonance spin-spin relaxation rate images were acquired and, after calibration, converted to absorbed dose distribution. The dose maps were compared with the dose distribution calculated using ion chamber in one plan and radiographic film for two plans. The dosimeters were irradiated by 4, and 10MV photons for doses in the range (4-10) Gy. The multiecho sequence was used for the evaluation of $\mathrm{T}_{2}$ (spin-spin relaxation times) in the irradiated gel dosimeters. (\%dd) percentage depth dose for (IMRT) intensity modulated radiation therapy / polymer gel \& Magnetic resonance imaging $=5.7 \%$ at $5 \mathrm{~cm}$, other the average dose are 10.45 for dose profile, where \%dd percentage depth dose for (IMRT) intensity modulated radiation therapy /ionization chamber and radiographic film $(\mathrm{IC} \& \mathrm{RF})=4.6 \%$ at $5 \mathrm{~cm}$ other the average dose are 10.45 for dose profile. DVH dose volume histogram for polymer gel \& magnetic resonance imaging = 94\%, but DVH dose volume histogram for point by point ionization chamber and radiographic film $=86 \%$.which lessince timing for protocol of integral part of verification radiation therapy.
\end{abstract}

Keywords: Magnetic Resonance Imaging, (MRI), N-isopropanol acrylamide (NIPAM), Intensity Modulated Radiation Therapy (IMRT) 
Military Technical College

Kobry Elkobbah,

Cairo, Egypt

April 19-21,2016

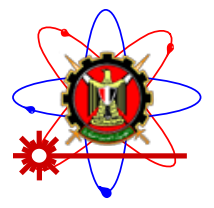

$8^{\text {th }}$ International Conference on

Mathematics and Engineering Physics (ICMEP-8)

\section{INTRODUCTION}

Polymer gel dosimetry is a technique that has the ability to map absorbed radiation dose distributions in three dimensions (3D) with high spatial resolution. Polymer gel dosimeters offer a number of advantages over traditional dosimeters such as ionization chambers, thermoluminescent dosimeters (TLD), one dimensential and radiographic film. Two-dimensential (2D) These advantages include independence of radiation direction, radiological soft tissue equivalence, integration of dose for a number of sequential treatment fields, and perhaps most significantly, evaluation of a complete volume at once. For reviews of polymer gel dosimetry systems see the proceedings of the DOSGEL International Conferences on Radiotherapy Gel Dosimetry (DOSGEL ,2004). The first polymer gel dosimetry system that maintained 3D absorbed dose information methylenebis-acrylamide (bis) and acrylamide (AA) co-monomers consisted of N,N infused in an aqueous agarose matrix. The purpose of this work was to evaluate the $\mathrm{N}$-isopropyl acrylamide (NIPAM) gel dosimeter and optimize the protocol for MRI imaging of gel dosimeters for radiation therapy application.

\section{MATERIAL and METHODS}

\section{Gel manufacture}

Polymer gels were manufactured using $5 \%$ gelatin, $30 \%$ Iso Propanol, and $5 \mathrm{mM}$ tetrakis hydroxyl methyl phosphonium chloride as antioxidant. The total amount of monomer N-Iso Propanol acrylamide, and cross linker (N,N' bis acrylamide, SigmaAldrich) were varied as needed (6-20) \%T while maintaining equal weights (i.e.50 \%C) of monomer and cross linker in each gel. The total amount of gel manufactured depended on the study $0.25-1 \mathrm{~L}$. To begin manufacture of iso propanol based normoxic gels, water and iso propanol were heated to $30{ }^{\circ} \mathrm{C}$ at which point gelatin was added. The solution was further heated to $35{ }^{\circ} \mathrm{C}$ at which point the Bis cross linker was added. The solution was heated and stirred to $45{ }^{\circ} \mathrm{C}$, then cooled to $37{ }^{\circ} \mathrm{C}$ and the NIPAM was added. Once all monomer was dissolved, THPC was added. Prepared gel was transferred to $20 \mathrm{~mL}$ scintillation vials. 
Military Technical College

Kobry Elkobbah,

Cairo, Egypt

April 19-21,2016

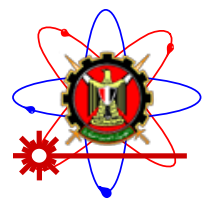

$8^{\text {th }}$ International Conference on

Mathematics and Engineering Physics (ICMEP-8)

\section{Gel irradiation}

Gels were irradiated using a Varian Clinac linear accelerator (Varian Inc, Palo Alto, CA, USA) using $6 \mathrm{MeV}$ photon, a $10 \times 10 \mathrm{~cm}^{2}$ field size, and a dose rate of 400cGy / min at $1.5 \mathrm{~cm}$ depth in water, for dose response studies, gels were irradiated in a customized phantom to between 4-10 Gy. For the imaging application, gels were irradiated in an immobilization device with 3 separate irradiations: (i) a single PDD with 4 Gy at $\mathrm{d}_{\max }$, (ii) a two-field cross ( 10 Gy at $\mathrm{d}_{\max }$ ), and (iii) a 3-field irradiation. The single and 2-field irradiations were used to generate a calibration curve for the polymer gel dosimeters. This calibration was then applied to the 3-field irradiation in order to convert relative response to dose. All treatment planning was performed using linear accelerator.

\begin{tabular}{|c|c|c|}
\hline Monomer & N-isopropylacylamide (NIPAM) & $3 g$ \\
\hline Crosslinker & N,Ń-methylene-bis acrlamide (Bis) & $3 g$ \\
\hline Gelatin & & $5 g$ \\
\hline Water & & 89 \\
\hline Antioxidant & Tetrakis (hydroxymethl) phosphonium chloride (THPC) & $10 \mathrm{mMol}$ \\
\hline
\end{tabular}

Table.1 Chemical composition of the NIPAM gel dosimeter

\section{Imaging (MRI Relaxation Time Imaging)}

A $0.5 \mathrm{~T}$ commercial MRI imaging system (Gyroscan $\mathrm{T}_{5}$ /Philips) was used for imaging purposes. A special wooden mold was constructed to fix in the head coil. The water tank also was stuck to this wooden mold to prevent dislocation of the phantom in the head coil in scanning processes before and after irradiation. The scanning protocols were also identical for before and after irradiation. The data in the MRI console was transferred to the computer (Gyroview) work's station for analysis. For each image an average region of interest (ROI) was obtained and the value of noise was subtracted from this ROI. The data of the signal intensity for after irradiation was subtracted from before irradiation data to obtain the variation of signal intensity (I) due to irradiation for each region. In this work, two imaging protocols named spin echo (SE) and gradient echo (GRE) were used. In SE technique scanning parameters were: $\mathrm{TE}=11 \mathrm{~ms}, \mathrm{TR}=100,120,150,200,250,350,500$, 1000, 2000, 4000ms. Slice thickness $=10 \mathrm{~mm}$, Gap thickness $=0 \mathrm{~mm}$, NSA=2 In GRE technique imaging parameters were: $\mathrm{TE}=11 \mathrm{~ms}$, $\mathrm{TR}=500 \mathrm{~ms}$. Flip angles $=30,60,75,90$ MRI allows the measurement of the longitudinal and transverse relaxation rates $\left(\mathrm{R}_{1}\right.$ and 
Military Technical College

Kobry Elkobbah,

Cairo, Egypt

April 19-21,2016

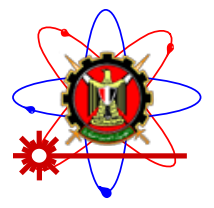

$8^{\text {th }}$ International Conference on

Mathematics and Engineering Physics (ICMEP-8)

$\mathrm{R}_{2}$ ) of the dosimeter gels, from which dose maps can be calculated. Conventionally, the corresponding relaxation times are measured, from which the rates can be computed. Relaxation times are measured by applying radiofrequency (RF) pulses to excite the magnetization of the spin system, and then sampling during the return to equilibrium. The transverse relaxation time $\left(T_{2}=1 / R_{2}\right)$ is measured by fitting data collected from at least two points on the transverse relaxation curve following excitation. Knowledge of the RF homogeneity of the RF coils used is useful to assess the effects of sample placement within the coil, which may affect the signal-to-noise ratio in different regions of a gel.Variation in measured may result from many factors, including changes in RF coil tuning, physical position within the coil, coil loading, imaging slice orientation and room temperature.

\section{Evaluation of polymer gel dosimeter}

Evaluations of dosimeters were performed on a Siemens Symphony Germany, 0.5T scanner in the head coil one day after irradiation. All samples of the polymer gel dosimeter were left inside the MRI room for a sufficiently long time (12 hours) to become temperature equilibrated with the room temperature. A multi echo sequence with 32 equidistant echoes was used for the evaluation of irradiated polymer gel dosimeters. The parameters of the sequence were as follows: TR 3000 ms, TE 20 ms, Slice Thickness 4 mm and field of favorite (FOV) $256 \mathrm{~mm}$.

\section{Calibration of the dosimeter}

Nine borosilicate glass vials were used to obtain calibration curves. Vial 1 is designated as the unirradiated vial. Vials 2-4 are irradiated with $4 \mathrm{MV}$ photons to total doses of 1, 4 and 7Gy, respectively, at a dose rate of $250 \mathrm{MU} / \mathrm{min}$. Vials 5-9 are irradiated with $10 \mathrm{MV}$ photons. Vials 5 and 6 are irradiated to a total dose of 1 Gy with a dose rate of 400 and $500 \mathrm{MU} / \mathrm{min}$, respectively; Vials 7-9 receive total doses of 4, 7 and 9 Gy, respectively at dose rate of $400 \mathrm{MU} / \mathrm{min}$.the cylindrical vials are placed in a cubic waterfilled phantom (35 cm x $35 \mathrm{~cm}$ x $38 \mathrm{~cm}$ ) where a photon beam from the Varian Clinac $21 \mathrm{EX}$ is administered parallel to the cylindrical axis. The vials are positioned vertically at the bottom of the water tank with approximately $10 \mathrm{~cm}$ of water above the vials. A gantry angle of $0^{\circ}$ and a field size of $10 \times 10 \mathrm{~cm}^{2}$ is used to irradiate the tank. The Varian Clinac 
$21 \mathrm{EX}$ is calibrated to give a dose of $1 \mathrm{cGy} / \mathrm{MU}$ at $\mathrm{d}_{\max }\left(\mathrm{SSD}=100 \mathrm{~cm}, \mathrm{FS}=10 \mathrm{x} 10 \mathrm{~cm}^{2}\right)$, where is at a depth of $1.2 \mathrm{~cm}$ for $4 \mathrm{MeV}$ and $2.5 \mathrm{~cm}$ for $\mathrm{d}_{\max } 10 \mathrm{MV}$. The radiation beam passes through $1 \mathrm{~cm}$ acrylic and $1 \mathrm{~mm}$ glass at the bottom of the tube. Because the MRI slices are $2 \mathrm{~mm}$ thick, it is expected that the slice containing the maximum dose is slice 1 for the $4 \mathrm{MV}$ photons and slice7 or 8 for the 10MV photons. Because of the potential for vial misalignment, the slice at which dmax occurs is not certain. For the background vial, transverse relaxation rates $\left(\mathrm{R}_{2}\right)$ are computed for slices 6,7 and 8 for the $10 \mathrm{MV}$ photons and slices 1,2 and 3 for the $4 \mathrm{MV}$ photons. The smallest value observed in these $\mathrm{R}_{2}$ slices is designated as the value for vial 1 . For the irradiated vials, one axial slice in each vial receives the desired dose $R_{2}$ at $d_{\max }$. Within these vials, is computed for the first axial slices 6,7 and 8 for the $10 \mathrm{MV}$ beam and slices 1,2 and 3 for the $4 \mathrm{MV}$ beam. The largest value is used as the $R_{2}$. A graph of vs. absorbed dose is produced, which is the calibration curve. Two calibration curves are computed, one that includes background subtraction (yintercept $=0$ ) and one that does not include background subtraction (non-zero intercept). The slope of the linear portion of the calibration curve gives the gel sensitivity. The storage, irradiation and temperature during MR imaging of the gel vials used for dose calibration and the large experimental gel were kept under identical conditions. All MRI scanning is performed at the same time post-irradiation.

\section{RESULTS and DISCUSSION}

The polymerization reaction is found to be stabilize at $15 \mathrm{~h}$ post-irradiation. Spatial stability investigations reveal a small overshoot in response for gels imaged later than $36 \mathrm{~h}$ post-irradiation. Based on these findings, it is recommended that the modified gel formulation could be imaged between (15-36) hours after irradiation. Intra- and inter-batch reproducibility is found to be excellent over the entire range of doses studied (0-20) Gy. A significant dose rate dependence is found for gels irradiated between (100-600) MU/1min. The $R_{2}$-dose calibration curves for the 4 and 10MV irradiation beams are shown in Figures1 and 2, respectively. The 10MV calibration curves were used to obtain dose rate $\left(R_{2}\right)$ maps from the polymer gel. The unit for dose is Gy, while the unit for the relaxation is inverse second. Shown in the graphs are the slope, $y$-intercept and chi-squared $\left(\mathrm{R}^{2}\right)$ values for both beams. The graphs are linear up to at least 7.14Gy $\left(\mathrm{R}^{2}=0.989\right)$ for the $4 \mathrm{MV}$ 
photons and 9.18 Gy $\left(\mathrm{R}^{2}=0.994\right)$ for $10 \mathrm{MV}$ photons. The y-intercept values were similar in both graphs with an intercept of 4.497 for $4 \mathrm{MeV}$ photons and 4.695 for the $10 \mathrm{MeV}$.

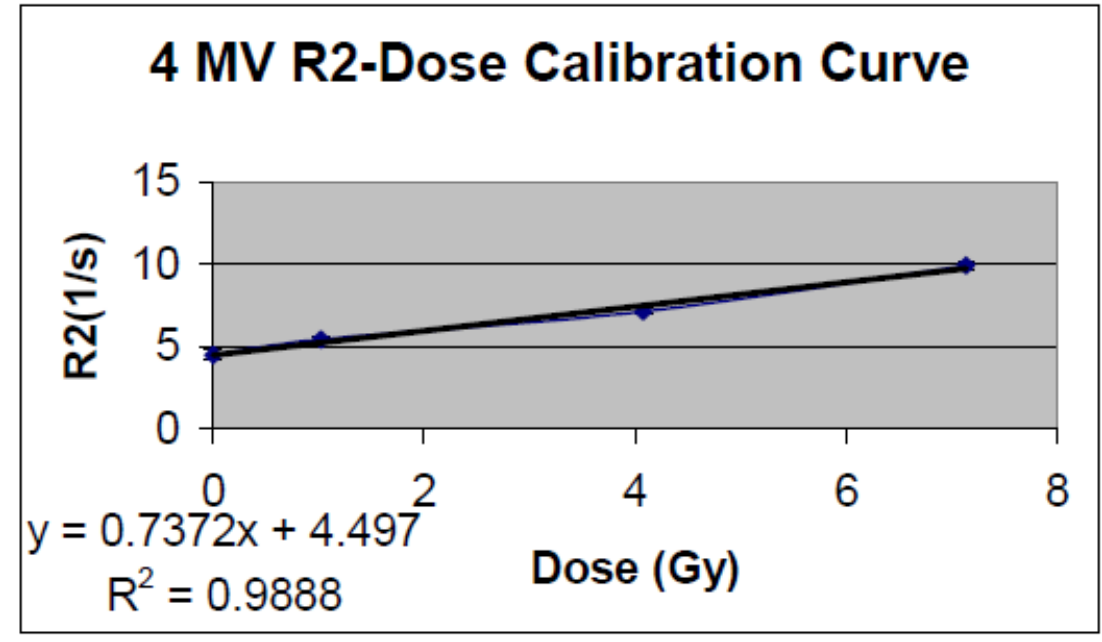

Figure.1: $4 \mathrm{MV}-\mathrm{R}_{2}$ Dose calibration curve obtained from the calibration vials.

$4 \mathrm{MV}-\mathrm{R}_{2}$ Dose calibration curve obtained from the calibration vials. Units for dose are in Gy and units for relaxation rate $\left(R_{2}\right)$ are inverse seconds $(1 / S)$. Three vials were irradiated to $1.02 \mathrm{~Gy}, 4.08 \mathrm{~Gy}$ and $7.14 \mathrm{~Gy}$, while one vial was left un irradiated for a background measurement. Also shown is the linear fit to the line and $\mathrm{R}_{2}$ value.

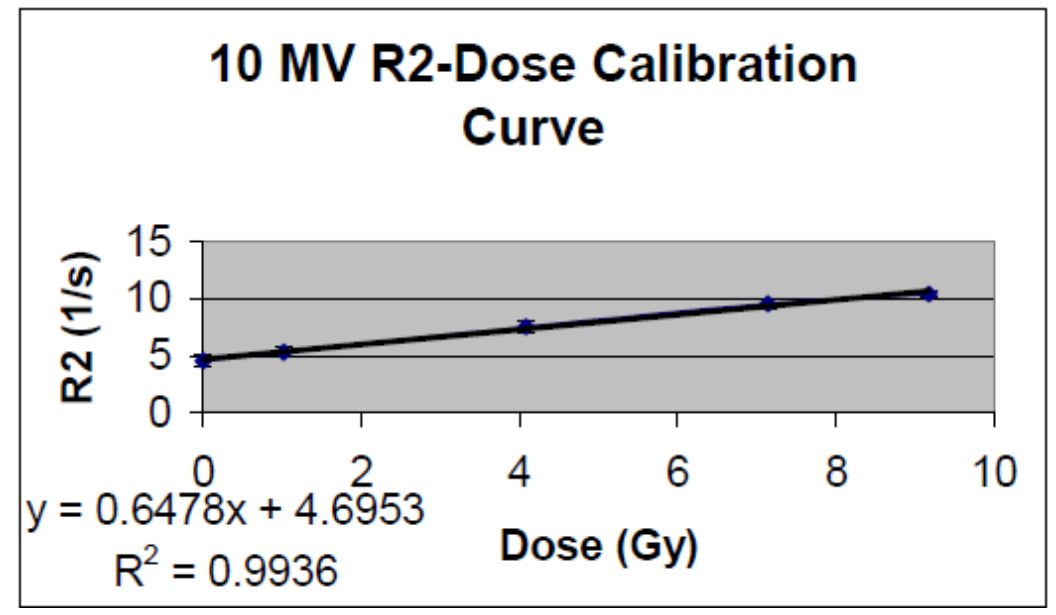

Figure. 2: $10 \mathrm{MeV}$ - $\mathbf{R}_{2}$ Dose calibration curve obtained from the calibration vails.

Units for dose are in Gy and units for relaxation rate $\left(R_{2}\right)$ are inverse seconds (1/S). Four vials were irradiated to $1.02 \mathrm{~Gy}, 4.08 \mathrm{~Gy}, 7.14 \mathrm{~Gy}$, and $9.18 \mathrm{~Gy}$ while one vial was left un irradiated for a background measurement. Also shown is the linear fit to the line and $R_{2}$ value. 


\section{Depth-dose method}

A long test tube of gel is positioned vertically in a water tank and irradiated from the closed end with a single radiation beam. This results in the gel recording a characteristic $\mathrm{R}_{2}$ “depth-dose" distribution. These data may be plotted against a known depth-dose distribution for the beam size and energy, or against ion chamber measurements in an identical geometry. To adequately cover the dose range 0-10 Gy, a number of short test tubes of gel irradiated to different doses should be used in preference to a single, long test tube owing to the potential limitations of RF coil homogeneity. At each depth, several adjacent points may be averaged together to increase the signal-to-noise ratio. Two $80 \mathrm{ml}$ flasks irradiated to $8.5 \mathrm{~Gy}$ and 5 Gy were used in this example. The gel shows good sensitivity and linearity up to $7 \mathrm{~Gy}$. Errors on the slope and intercept are $0.4 \%$ and $0.6 \%$, respectively. Overlaid onto this figure are data points obtained using the "multi flask" method with gel from the same batch. The five points correspond to flasks irradiated with $10 \times 10 \mathrm{~cm}^{2}$ fields to doses of 2, 4, 6, 8 and $10 \mathrm{~Gy}$. Errors on the slope and intercept for the five-point fit are $2.5 \%$ and $3.7 \%$, respectively. Other calibration methods have also been reported. Rather than generating a $T_{2}$ map of the calibration phantom, two $T_{2}$ weighted images with widely differing echo times may be used to generate a look-up table of transverse relaxation rates for known absorbed doses.

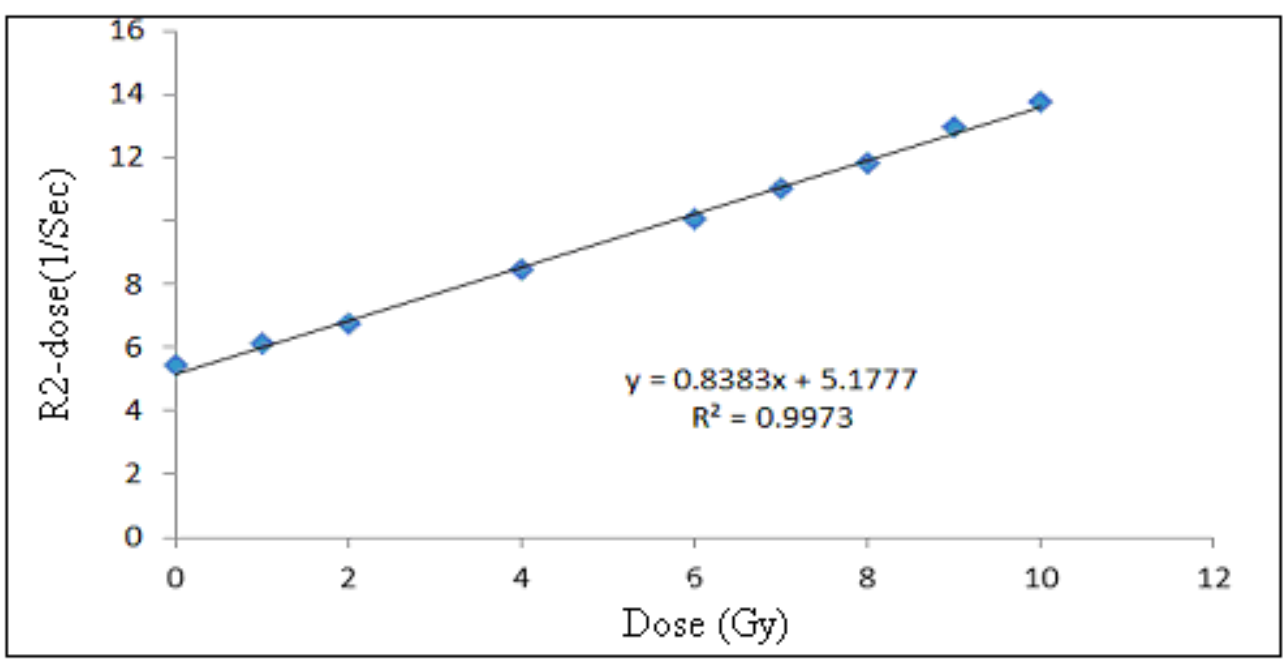

Figure 3. Dose response curve for 10MV photon beam at 10Gy. 
Military Technical College

Kobry Elkobbah,

Cairo, Egypt

April 19-21,2016

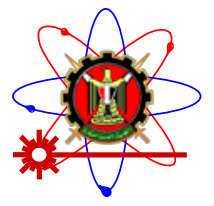

$8^{\text {th }}$ International Conference on Mathematics and Engineering Physics (ICMEP-8)

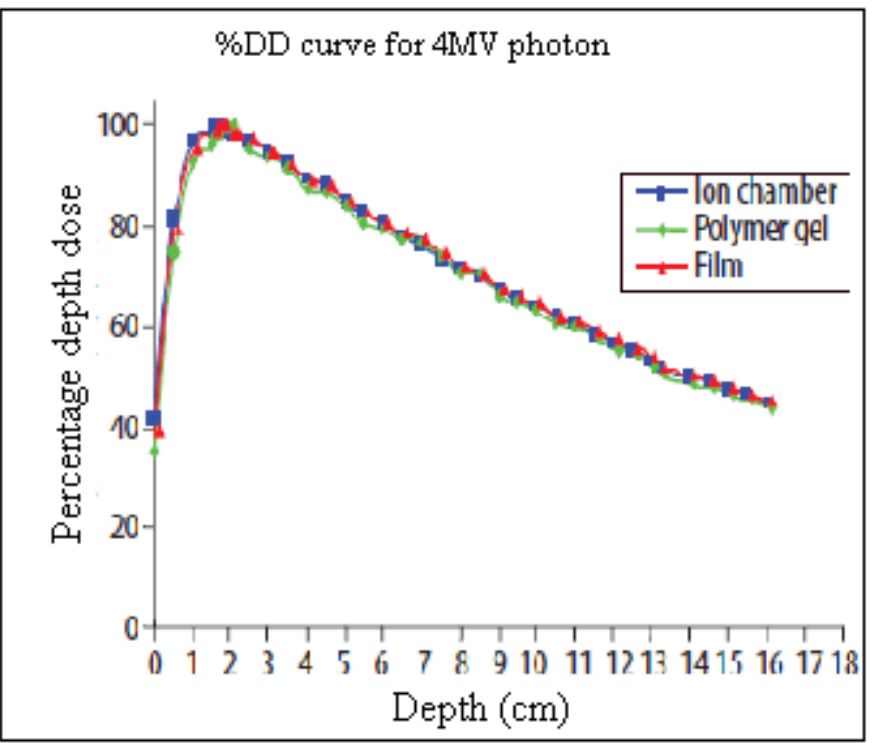

Figure 4. \%DD curves for 4MV photon beam

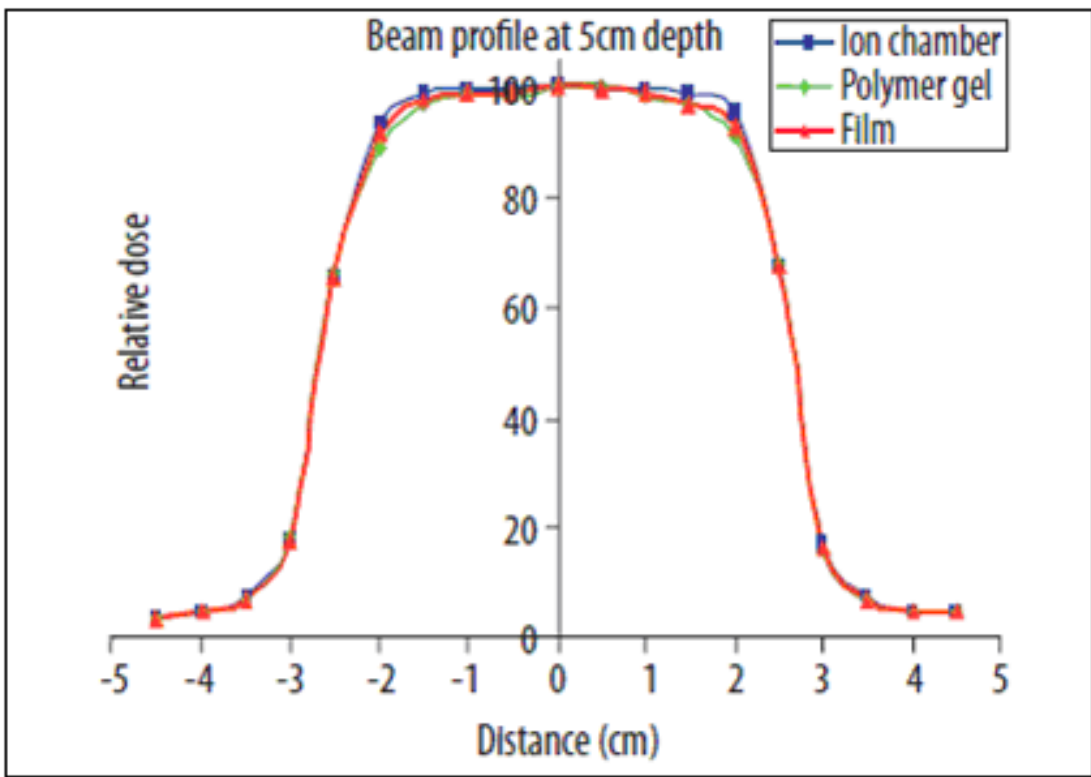

Figure 5. Profile beam dose for $4 \mathrm{MV}$ photon at $5 \mathrm{~cm}$ depth. 


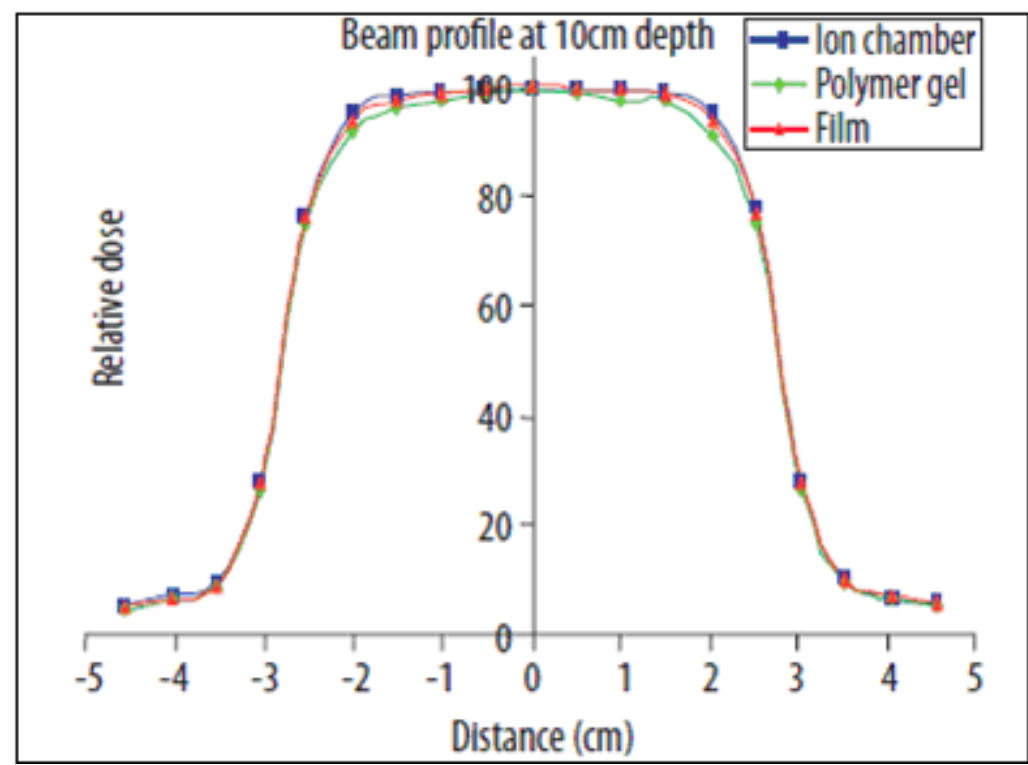

Figure 6. Profile beam dose for $10 \mathrm{MV}$ photon at $10 \mathrm{~cm}$ depth.

\section{CONCLUSIONS}

Polymer gel dosimetry offers a method of acquiring 3D maps of complex radiotherapy dose distributions with a spatial resolution of the order of I mm, depending upon the scanning and imaging specifications As a result of these complicated treatment techniques there is a need for a 3-dimensional (3D) dose verification system. However, currently available dosimeters such as ion chambers, diodes, thermoluminescent dosimeters and films are limited to point (or) planar measurement. Gel dosimetry attempts to meet the requirements of $3 \mathrm{D}$ radiation dose distribution. Gel dosimetry is tissue equivalent and it acts as a phantom as well as dosimeter so there is no need for dose perturbation correction, and no expensive for clinical use, was manufactured in normal atmospheric conditions. The gel was irradiated using a Siemens Primus linear accelerator. The percentage depth doses and profiles were deduced. The same study was carried out using radiation field analyzer RFA-200 with RK-ion chamber and film and compared with polymer gel measurements polymer gel dosimeter measurement was in agreement with ion chamber and film measurements. This preliminary study was conducted to evaluate the feasibility of using MRI-based polymer gel dosimeter for clinical use. The results of this study encourage further use of MRI in conjunction with polymer gel for 3D radiation dose measurements. 


\section{REFERENCES}

1. MATHER, M., WHITTAKER, A.K., BALDOCK, C., MRI evaluation of polymer gel dosimeters, Phys. Med. Biol. 47 (2008) 1449-1458.

2. BALDOCK, C., BURFORD, R.P., BILlingHAM, N., COHEN, D., KEEVIL, S.F., Polymer gel composition in magnetic resonance dosimetry, Proc. Soc. Magn. Reson. Med. (2008) 1594.

3. MARYANSKI, M.J., AUDET, C., GORE, J.C., Effects of crosslinking and temperature on the dose response of a BANG polymer gel dosimeter, Phys. Med. Biol. 42 (2004) 303-311.

4. FARAJOLlAHI, A.R., BONNETT, D.E., RATCLIFFE, A.J., AUKETT, R.J., MILLS, J.A., An investigation into the use of polymer gel dosimetry in low dose rate brachytherapy, Br. J. Radiol. 72 (2010) 1085-1092.

5. KEALL, P.J., BALDOCK, C., A theoretical study of the radiological properties and water equivalence of Fricke and polymer gels used for radiation dosimetry, Australas. Phys. Eng. Sci. Med. 22 (2007) 85-91.

6. RAMM, U., et al., Three-dimensional BANGTM gel dosimetry in conformal carbon ion radiotherapy, Phys. Med. Biol. 45 (2010).

7. MARYANSKI, M.J., IBBOTT, G.S., EASTMAN, P., SCHULZ, R.J., GORE, J.C., Radiation therapy dosimetry using magnetic resonance imaging of polymer gels, Med. Phys. 23 (2001) 699-705.

8. SALOMONS, G.J., PARK, Y.S., McAULEY, K.B., SCHREINER, L.J., Temperature increases associated with polymerization of irradiated PAG dosimeters, Phys. Med. Biol. 47 (2009) 1435-1448.

9. MARYANSKI, M.J., AUDET, C., GORE, G.C., Dose response of BANG polymer gel dosimeter: Temperature dependence, Med. Phys. 22 (2007) 951.

10. HARALDSSON, P., BÄCK, S.Å.J., MAGNUSSON, P., OLSSON, L.E., Dose response characteristics and basic dose distribution data for a polymerization based dosimeter gel evaluated using MR, Br. J. Radiol. 73 (2010) 58-65.

11. McJURY, M., OLDHAM, M., LEACH, M.O., WEBB, S., Dynamics of polymerization in polyacrylamide gel (PAG) dosimeters: (I) ageing and long-term stability, Phys. Med. Biol. 44 (2009) 1863-1873. IAEA-CN-96/117 351

12. DE DEENE,Y., HANSELAER, P.,DE WAGTER, C.,ACHTEN, E., DE NEVE, W., An investigation of the chemical stability of a monomer/polymer gel dosimeter, Phys. Med. Biol. 45 (2010) 859-878. 
13. KEALL, P.J., BALDOCK, C., A theoretical study of the radiological properties and water equivalence of Fricke and polymer gels used for radiation dosimetry, Australas. Phys. Eng. Sci. Med. 22 (2007) 85-91.

14. MARYANSKI, M.J., IBBOTT, G.S., EASTMAN, P., SCHULZ, R.J., GORE, J.C., Radiation therapy dosimetry using magnetic resonance imaging of polymer gels, Med. Phys. 23 (2004) 699-705.

15. Maryanski, M.J., R.J. Schulz, G.S. Ibbott, J.C. Gatenby, J. Xie, D. Horton and J.C. Gore, 1994. Magnetic resonance imaging of radiation dose distributions using o polymer gel dosimeter. Phys. Med. Biol., 39: 1437-1455.

16. Maryanski, M.J., G.S., Ibbott, P. Estman, R.J. Schulz and J.C. Gore, 1996. Radiation therapy dosimetry using magnetic resonance imaging of polymer gels. Med.Phys., 23: 699-705.

17. Gore, J.C., Y.S. Kang and R.J. Schulz, 1984. Measurement of radiation dose distributions by Nuclear Magnetic Resonance (NMR) imaging. Phys.Med. Biol., 29: 1189-1197.

18. De Deene, Y., 2004. Essential characteristics of polymer gel dosimeters: Third international conference radiotherapy gel dosimeter. J. Phys. Conf. Ser. 3: 34-57.

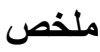

تو اكب التطور ات الحديثة فى تقنيات علاج الاور ام بالاشعاع ثلاثية الابعاد وسيلة للتحقق من ايصال الجر عة

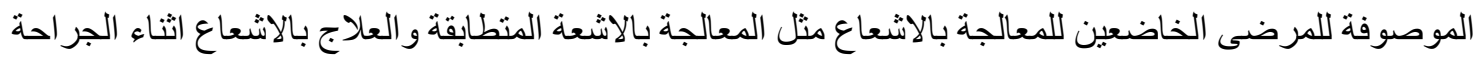

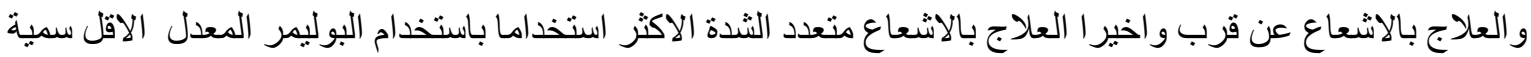
من البوليمر جيل المستخدم فى معامل الكيمياء الحيوية. ومع التطور ات المتلاحقة للبوليمر جيل امكن تقليل السمية العالية بة و امكن استخدامة فى التحقق من الجر عة ثلاثية الابعاد المعطاة للمرضى نظر الخاصية البلمرة للبوليمر و التصوير باشعة الرنين المغناطيسى عقب تشعيع البوليمر بجر عة محددة ومعرفة سلفا امكن حسابات معدل الاسترخاء

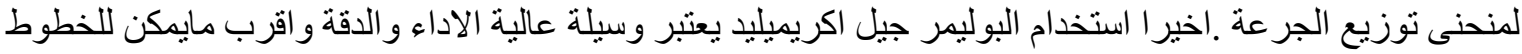
الارشادية .فى التحقق من الجر عة المعطاة للمرضى .....بحسابات خر ائط توزيع الجر عة من منحنى الجر عة العيارية مع معدل الاسترخاء، المنحيات العيارية عند 6 مليون فولت وايضا 10 مليون فولت ومن ثم التحقق بالبوليمر جيل للقر اءات المعطاة من جر عة العمق، توزيع الجر عات على منحنى الناقوس وحجم تمثيل للجر عات بالرسوم البيانية. 